\title{
CENTRALIDADE URBANA: REFLEXÕES SOBRE VITÓRIA DA CONQUISTA E
}

ARACAJU

\author{
Urban centrality: reflections about Vitória da Conquista e Aracaju
}

\section{Centralidad urbana: reflexiones sobre Victoria de la conquista y Aracaju}

\author{
Adriana David Ferreira Gusmão ${ }^{1}$ http://orcid.org/0000-0003-1569-7384 \\ Vera Lúcia Alves França ${ }^{2}$ http://orcid.org/0000-0002-0570-4459
}

\footnotetext{
${ }^{1}$ Doutora em Geografia pela Universidade Federal de Sergipe- Brasil . Professora adjunta do Departamento de Geografia da Universidade Estadual do Sudoeste da Bahia-Brasil - adrianadgusmao@ gmail.com

${ }^{2}$ Doutora em Geografia pela Universidade Estadual Paulista Júlio de Mesquita Filho, professora do Núcleo de Pósgraduação em Geografia (NPGEO) Universidade Federal de Sergipe- Brasil - verafranca@gmail.com
}

\section{Resumo}

Este artigo tem como objetivo apresentar aspectos da centralidade urbana de duas cidades do Nordeste brasileiro: Vitória da Conquista e Aracaju. A primeira delas é uma capital regional do Estado da Bahia, com situação privilegiada no sudoeste baiano. Aracaju é capital do Estado de Sergipe e se caracteriza pela primazia no subsistema urbano que compõe. Foi realizada revisão bibliográfica e trabalho de campo para verificar as condições locais. As cidades apresentam forte centralidade sobre as áreas em que se situam e, dentre as funções, destacam-se as de educação e saúde, com capacidade para atrair pessoas de municípios distantes e até de outros estados. O fortalecimento da centralidade dessas cidades vem se acentuando nas últimas décadas, sendo favorecida pela rede rodoviária.

Palavras-chave: Centralidade. Funções Urbanas. Fixos e Fluxos.

\begin{abstract}
This article aims to present aspects of the urban centrality of two cities of Northeastern Brazil: Vitória da Conquista and Aracaju. The first of these is a regional capital of the State of Bahia, with a privileged situation in southwest Bahia. Aracaju is the capital of the state of Sergipe and is characterized by primacy in the urban subsystem that makes up. A literature review and field work were performed to verify local conditions. Cities have a strong centrality over the areas in which they are located and, among the functions, stand out those of education and health, with the capacity to attract people from distant municipalities and even from other states. The strengthening of the centrality of these cities has been increasing in recent decades, being favored by the road network.
\end{abstract}

Keywords: Keywords: Centrality. Urban Functions. Fixed and Flows. 


\section{Resumen}

Este artículo tiene como objetivo presentar aspectos de la centralidad urbana de dos ciudades del noreste de Brasil: Vitória da Conquista y Aracaju. La primera de ellas es una capital regional del Estado de Bahía, con una situación privilegiada en el suroeste de Bahía. Aracaju es la capital del estado de Sergipe y se caracteriza por la primacía en el subsistema urbano que lo conforma. Se realizó una revisión de la literatura y trabajo de campo para verificar las condiciones locales. Las ciudades tienen una fuerte centralidad sobre las áreas en las que están ubicadas y, entre las funciones, destacan las de educación y salud, con la capacidad de atraer a personas de municipios distantes e incluso de otros estados. El fortalecimiento de la centralidad de estas ciudades ha ido en aumento en las últimas décadas, siendo favorecido por la red de carreteras.

Palabras clave: Centralidad. Funciones urbanas. Fijos y Flujos.

Recebido em: 30/10/2019

Aceito para publicação em: 01/12/2019

\section{Introdução}

Os estudos sobre a cidade e o urbano sempre atraíram a atenção dos geógrafos e esse interesse tem subsidiado a análise espacial que se fundamenta na observação e aplicação do conhecimento científico sobre o desenvolvimento e função exercida pelos lugares.

Da Ágora, referência de centro cultural, econômico e político da Grécia ao conceito de centro na sociedade atual, há uma grande trajetória filosófica e teórica, com vasto referencial produzido. Apesar de muitos conceitos parecerem anticorpos para outros, cada um deles tem sua consistência se abordado à luz da realidade que comporta. No entanto, o protagonismo da cidade fundamenta-se no fato dela ser uma obra social e que, definitivamente, tem como marca a sua capacidade de ser centro, de exercer centralidade. Essa substantivação do fenômeno urbano apresenta um simbolismo e uma valorização que atribuem definições à cidade, ainda que a mesma deva ser considerada e discutida em sua totalidade de relações e contextos que ultrapassam os limites do urbano e formam a totalidade do espaço geográfico.

O espaço geográfico é formado pela dinâmica dos sistemas de objetos e dos sistemas de ação contendo as contradições a toda a mecânica do modo de produção em vigor (SANTOS,1996). Além disso, comporta os significados de centro urbano e centralidade como derivações das hierarquias construídas com base nas funcionalidades dos lugares, mas também, do status que cada área, cidade, município ou região recebe 
ao fazer parte de um circuito que, poderia ser representado por uma lógica construída a partir dos interesses econômicos e sociais. Assim, a hierarquia acaba por definir distintos significados que um lugar passa a assumir e que se encontram dispostos de formas variadas a depender da razão de estar na rede que estrutura a centralidade de uma localidade.

Centralidade urbana é a capacidade que uma cidade tem para atrair fluxos internos e externos para a aquisição de bens, de serviços e de informações. É a força de polarização de uma cidade a partir de sua localização e da oferta de bens e de serviços. Portanto, a centralidade está relacionada com a presença de fixos que atrai fluxos de diferentes pontos, resultando no intenso movimento do capital (SANTOS, 1996). Com a implantação da infraestrutura e de funções (os fixos), intensificam-se as trocas de informações e de mercadorias, as migrações permanentes e temporárias, novos empregos e novas relações socioculturais (os fluxos). Os fixos abrigam funções que vão ser exercidas pela cidade no atendimento aos seus moradores ou às pessoas de outros lugares, gerando os fluxos.

As cidades fazem parte de sistemas abertos que trocam energia através dos fluxos de pessoas, bens, serviços e de informações. Integrante de um sistema aberto, uma cidade não existe apenas para os seus moradores, mas, para os moradores de uma região bem mais ampla e, quanto maior for a diversidade da oferta de bens e de serviços, maior serão os fluxos. A cidade se retroalimenta dos recursos (capital) trazidos por pessoas vindas de outras cidades e lugares que reforçam e garantem a permanência de suas funções, assim como o surgimento de outras mais especializadas. Assim, quanto maior for o número de funções especializadas presentes na cidade, maior será sua capacidade de atrair pessoas de áreas mais distantes, ampliando assim, sua área de influência.

O presente artigo tem como objetivo destacar aspectos da centralidade urbana exercida pelas cidades de Vitória da Conquista e de Aracaju em seus respectivos entornos regionais, subcentros ou centros vizinhos. Além disso, enfoca características do espaço urbano das cidades mencionadas que aludem à polarização exercida pelas mesmas, por meio da oferta de serviços e de condições que cooperam para que fluxos diversos atravessem o cotidiano das localidades destacadas a ponto de torná-las centros econômicos, sociais, políticos, históricos e que retroalimentam a expansão horizontal das mesmas, além de conferir status de áreas centrais especializadas. 


\section{Centralidade Urbana: o caso de Vitória da Conquista/BA}

Com uma área de $3.743 \mathrm{Km}^{2}$, o município de Vitória da Conquista (Figura 1) é um dos mais extensos e mais populosos da Bahia e está localizado na microrregião do Planalto da Conquista, Sudoeste do Estado. A população do município é de 341.597 habitantes, segundo estimativas do IBGE, para 2019. O município tem um dos Produtos Internos Brutos (PIB) que mais crescem no interior do Estado, oferecendo em sua sede serviços e comércio diversificados, principalmente no tocante à educação e saúde, o que atraí grande volume de pessoas do seu entorno, definindo uma extensa área de influência desse centro urbano. Em 2016, o PIB do município alcançou R\$ 6.226.153.000,00, correspondendo a 2,40\% do PIB baiano.

Mapa 1 - Localização do Município de Vitória da Conquista, 2009

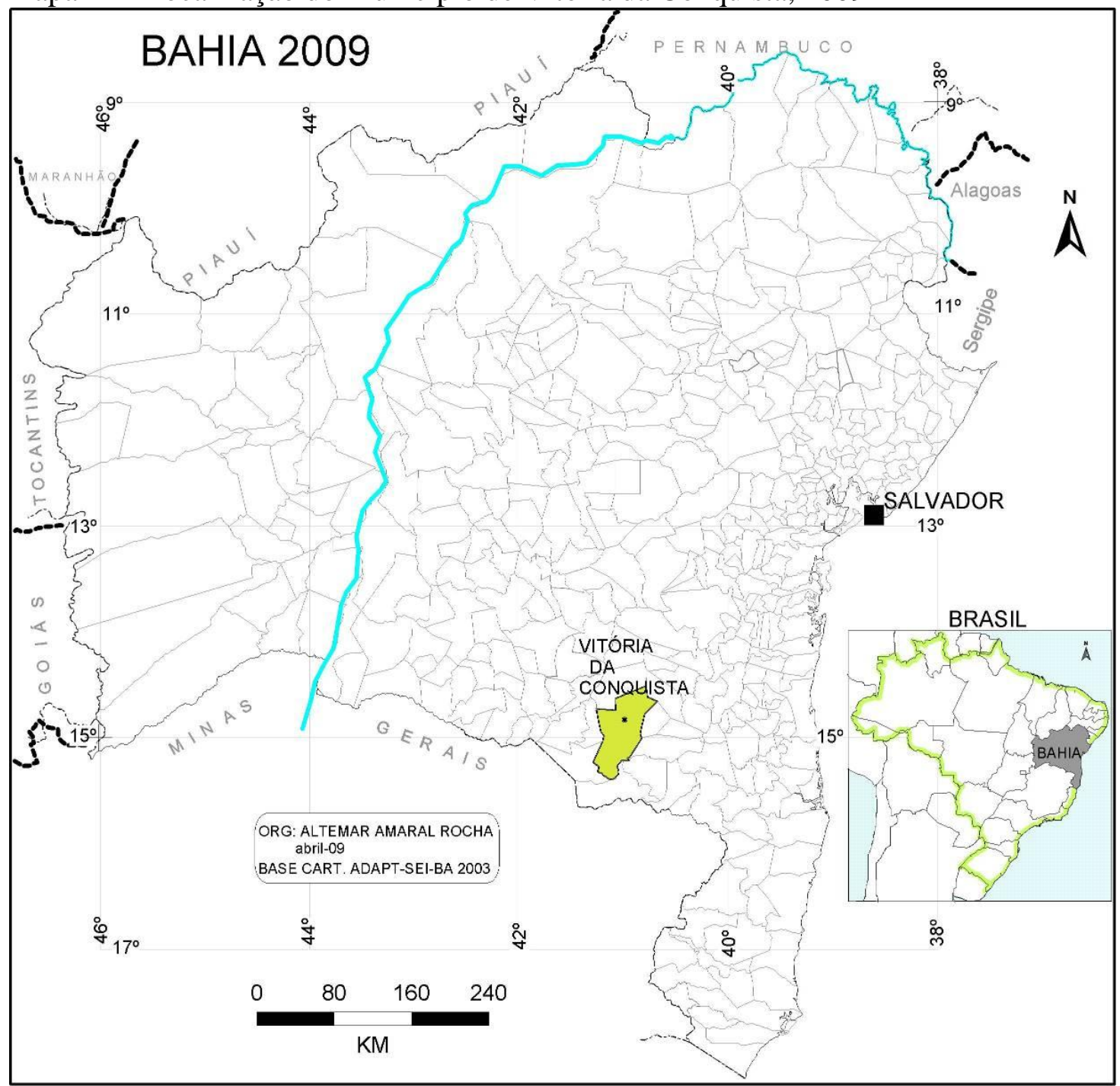

Fonte: Elaborado por Rocha (2009) 
A sede do município, a cidade de Vitória da Conquista, situada a, aproximadamente, 900 metros de altitude, se localiza em torno de três eixos rodoviários: no sentido norte-sul, a BR 116 (rio bahia), que permite o acesso tanto ao centro-sul como ao norte e nordeste, no sentido leste-oeste, a BA-415 (conquista - itabuna) com acesso ao litoral, e a BA-262 (conquista - brumado) que possibilita acesso ao oeste do estado e se constituindo na principal rota de entrada para a região centro-oeste do país (Mapa 2). a população residente na cidade de vitória da conquista é de 260.260 habitantes, de acordo com o censo demográfico do ibge, para o ano 2010, com expectativas de aumento significativo para os dias atuais.

Mapa 2 - Região Sudoeste da Bahia - Principais Rodovias, 2008

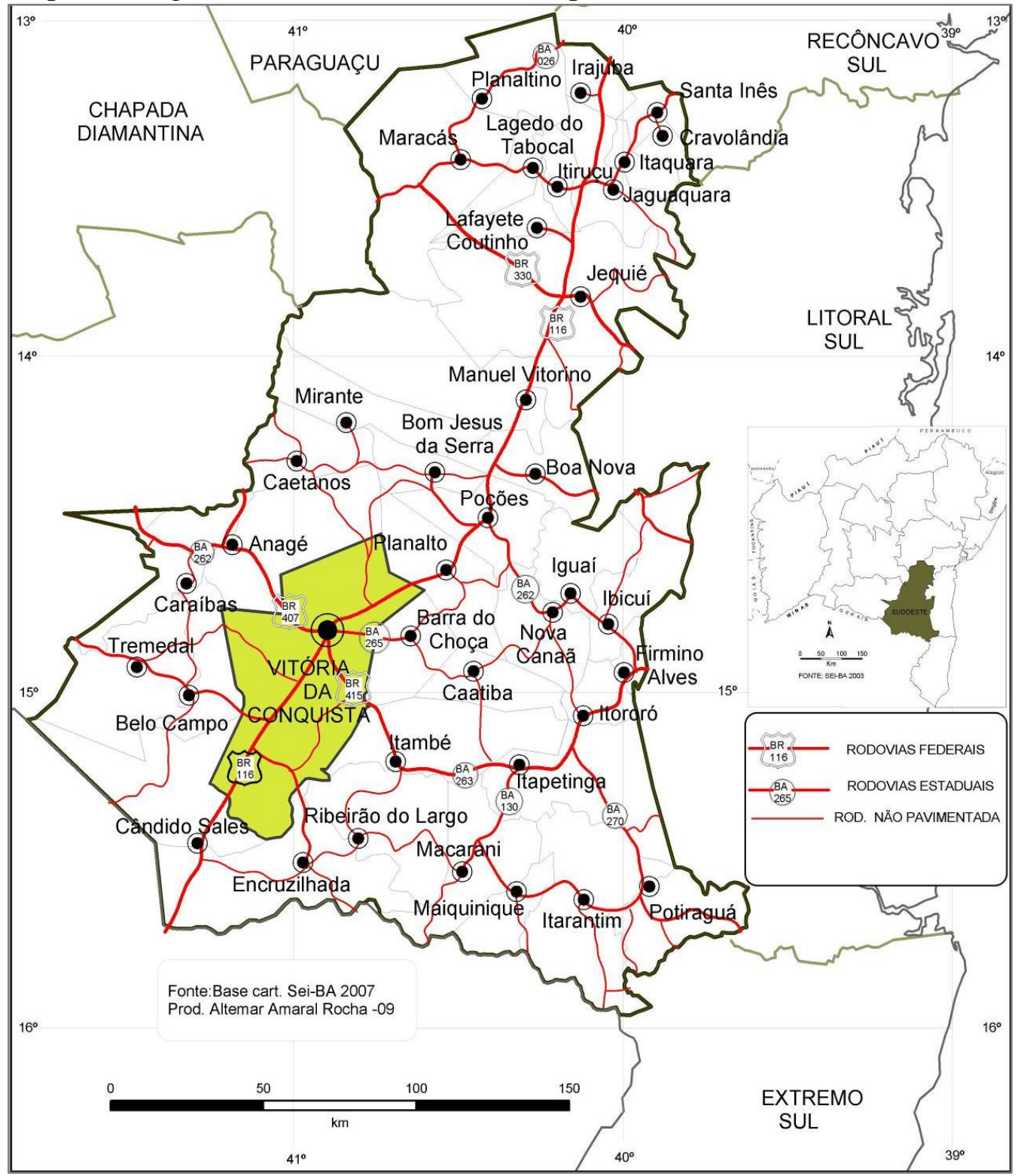

Fonte: Elaborado por Rocha (2008), dados da Sei-Ba (2003) 
Dentre outras razões, também por se localizar em um entroncamento rodoviário, que é vital para a Bahia e todo o Sudoeste, Vitória da Conquista vem se consolidando como um dos dez municípios mais dinâmicos do Brasil, de acordo com a Pesquisa 'Municípios mais dinâmicos do Brasil' constando no Atlas do Mercado Brasileiro de 2008, e figura como a terceira maior cidade do Estado da Bahia, apresentando o setor terciário mais desenvolvido da região, de tal modo que exerce função polarizadora em relação aos municípios circunvizinhos.

Até a década de 1940, a base econômica do município se fundou na pecuária extensiva. A partir daí, surgiria uma nova fase econômica e social com a cafeicultura e o comércio ocupando um lugar de grande destaque na economia local, tendo em vista novas condições de acessibilidade.

Em 1970, inicia-se o processo econômico baseado na cafeicultura e na indústria de transformação, com a criação do Distrito Industrial dos Imborés. O café alicerçou o desenvolvimento sócio - econômico do município por muitos anos, no entanto, a indústria não se consolidou de maneira plena. Parte das cidades do Brasil, principalmente aquelas da região Sudeste, tiveram seu processo de desenvolvimento calcado na industrialização e numa urbanização nem sempre equilibrada e planejada.

Apesar de Vitória da Conquista apresentar posição geográfica favorável e eminente potencial econômico, que, durante muito tempo, permeou o discurso sobre o município, este não participou de forma significativa do movimento industrial concentrado na década de 1970. Portanto, não foi beneficiado por nenhum movimento atrelado às políticas públicas tradicionais de desenvolvimento, sendo necessário construir alternativas de crescimento endógeno para o município.

A produção cafeeira entrou em crise, a partir do final dos anos de 1980, em decorrência da queda nos preços e dos longos períodos de estiagem. Assim, a característica de polo de serviços entra em relevo. A educação, a rede de saúde e o comércio se expandem, abrindo novas possibilidades de desenvolvimento local e regional. Sobre isso Lopes (2002) afirma que:

Nesse quadro recessivo, dois novos setores ligados à economia dos serviços despontam como potenciais de desenvolvimento para a economia de Vitória da Conquista. São eles os serviços de saúde e educação. Dentre os serviços de educação destaca-se o ensino superior pelo seu poder de alavancar o desenvolvimento regional através da formação de capital humano e pelos seus efeitos a montante e a jusante. Os efeitos a montante relacionam-se à criação de cursinhos pré-vestibulares, de escolas de segundo grau e de cursos de idiomas. 
Os efeitos a jusante relacionam-se aos gastos com investimentos e manutenção das IES, aos gastos de professores e funcionários empregados no ensino superior e aos gastos de alunos oriundos de outros municípios (LOPES, 2002, p. 31).

Com posição privilegiada e com uma infraestrutura econômica, política e administrativa bastante expressiva para o contexto regional, Vitória da Conquista atende a um grande contingente de pessoas que busca bens e serviços, tendo um raio de ação que promove a consolidação de uma grande região de influência.

Com a participação efetiva de Vitória da Conquista na oferta de serviços de saúde e educação, no Estado, verifica-se a partir do final da década de 1990, o aumento da oferta de ensino superior que vem promovendo uma intensa movimentação socioeconômica e espacial, não apenas na cidade, mas no Sudoeste Baiano, sobretudo, naqueles municípios que utilizam as vagas oferecidas em Vitória da Conquista. A oferta e a demanda por esse serviço têm conferido a condição de polo educacional de nível superior à cidade, pois esta conta, hoje, com uma boa infraestrutura direcionada ao setor. Sobre isso, Lopes (2002) afirma que:

O ensino superior destaca-se em Vitória da Conquista graças à ação polarizadora deste município na região Sudoeste da Bahia e à presença de uma universidade pública nova e emergente, a UESB. Estes elementos favorecem a formação de uma aglomeração especializada em ensino superior neste município. A ação polarizadora decorre, principalmente, da sua posição geográfica. Como já lembramos, Vitória da Conquista é o centro de serviços de uma região que abriga uma população em torno de 2 milhões de habitantes (LOPES, 2002, p.31).

A necessidade iminente de vagas em virtude do crescimento populacional, a necessidade de melhorar os níveis de escolaridade e de qualificação profissional, foram fatores que motivaram a ampliação da oferta de vagas, reduzindo a centralização do ensino superior na capital do Estado. A base da política de descentralização do ensino superior foi inspirada em uma das diretrizes do Programa de Ação Governamental que definia como meta a interiorização do desenvolvimento das regiões e pelo fortalecimento das políticas e programas.

Durante a expansão do ensino superior no Estado baiano foi criada a Universidade Estadual do Sudoeste da Bahia (1980), uma instituição pública de ensino superior, de natureza autárquica, regida pelos princípios do direito público e vinculada à Secretaria de Educação do Estado da Bahia. Atraídas pela UESB, foram criadas 
instituições privadas denominadas Faculdades de Ensino Superior que oferecem cursos diversos e atendem à uma fatia considerável da população da região. Portanto:

Nesta região, a presença de uma universidade pública forte é condição necessária para o surgimento e consolidação das IES privadas. Isto ocorre, dentre outros motivos, porque as IES privadas aproveitam-se da proximidade para compartilhar recursos (como capital humano, por exemplo) com a universidade pública. (LOPES, 2002, p )

O ensino superior que tem seus objetivos finais atrelados à inovação, profissionalização e à formação intelectual das pessoas se constitui num gerador de fixos e fluxos espaciais. Dessa maneira, a participação das instituições de ensino superior vincula-se não somente à produção do conhecimento, tão necessária à sociedade, mas, também na produção do espaço urbano e regional, confirmando uma das vertentes da centralidade urbana exercida por Vitória da Conquista (Diagrama 1).

Diagrama 1 - Relação entre a implantação/ampliação da oferta de ensino superior em Vitória da Conquista e a geração de novos sistemas de objetos.

\section{Implantação de Instituições de Ensino Superior em Vitória} da Connuista

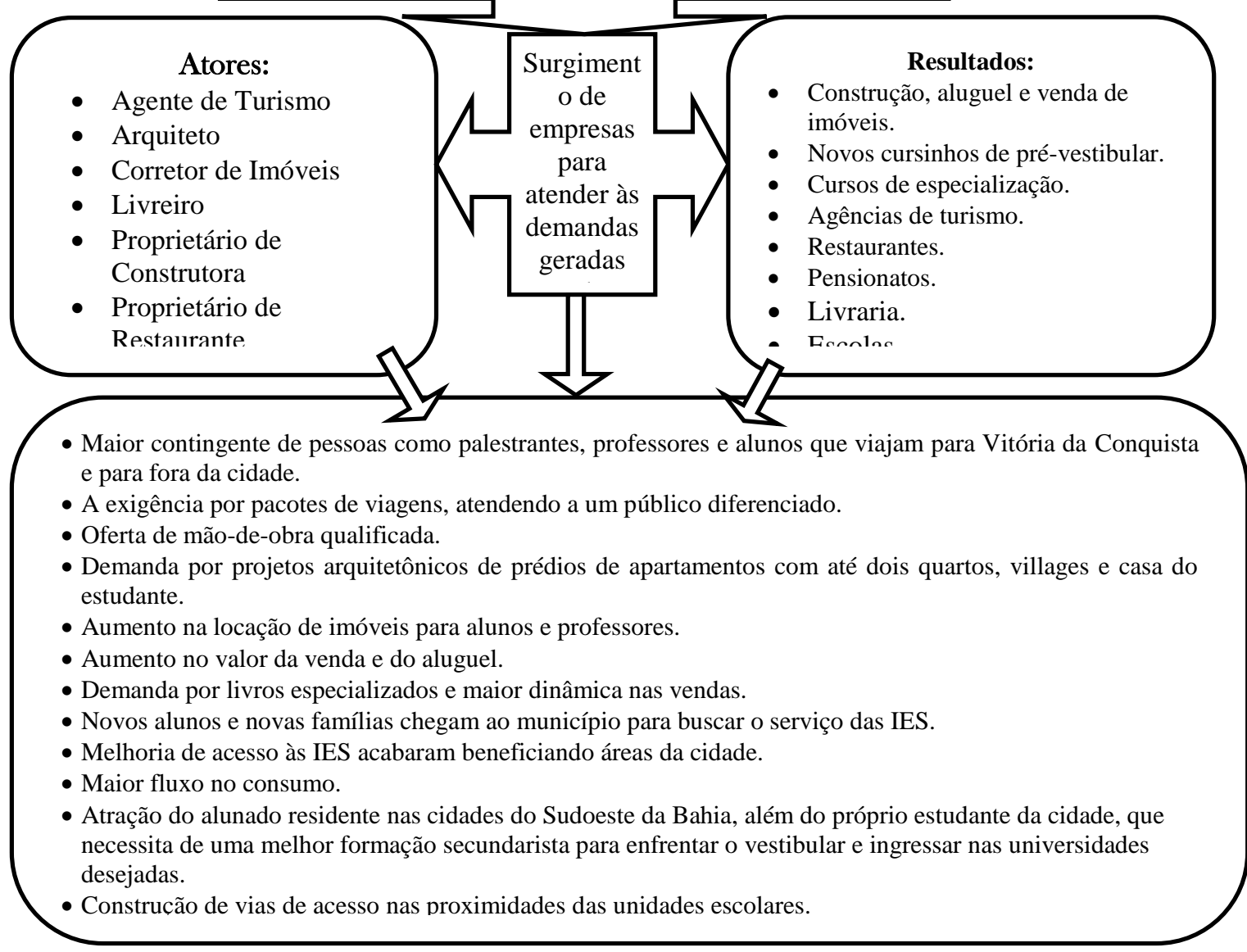

Fonte: Gusmão (2009). 
A centralidade urbana de Vitória da Conquista, com relação aos serviços educacionais, se expressa por meio da consolidação de uma área de influência que chega a alcançar mais de 100 municípios, o que confirma a hipótese desta cidade ser considerada um polo educacional regional. (mapa 3).

Mapa 3- Fluxos para o Ensino Superior em Vitória da Conquista - BA

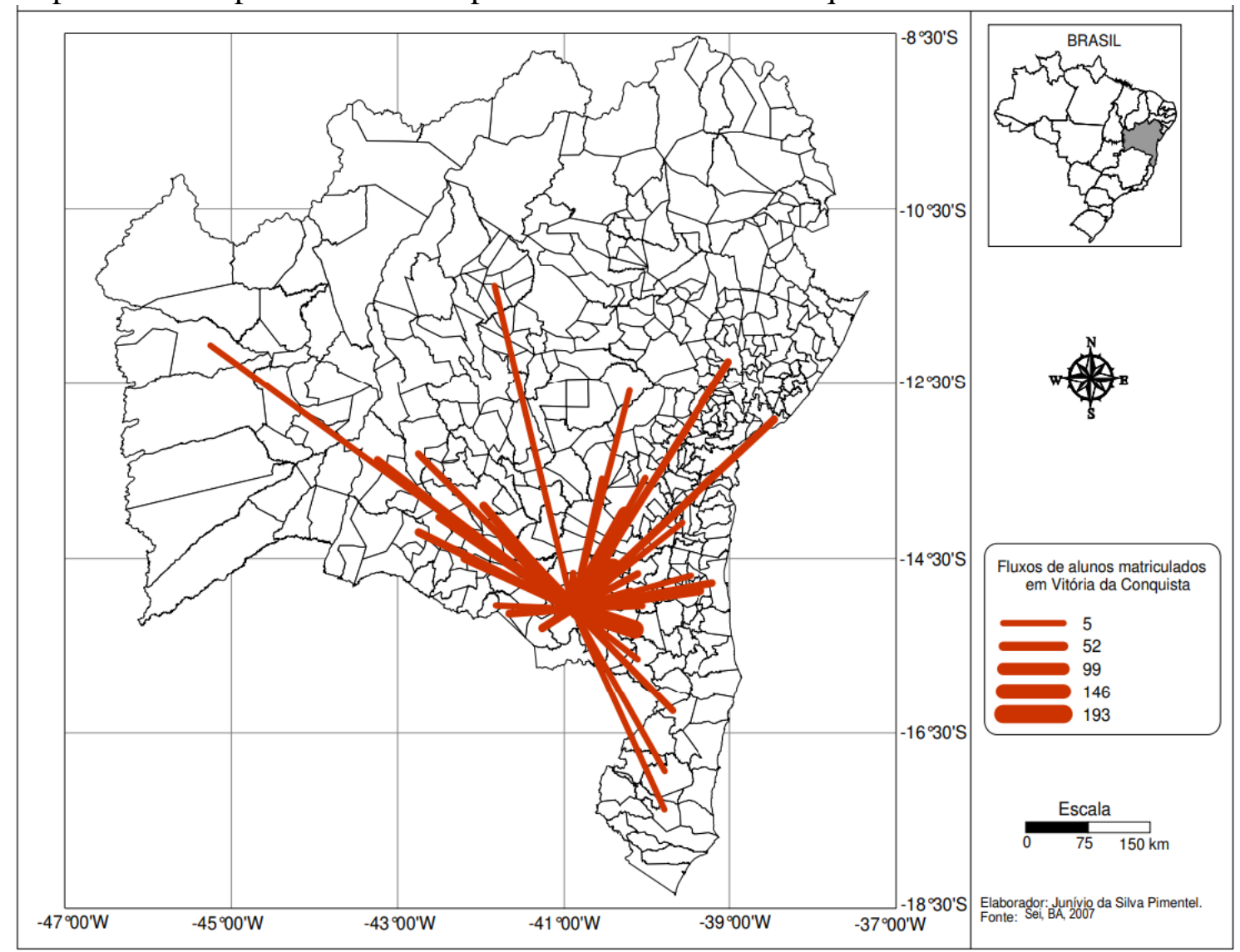

Fonte: Gusmão, 2009.

A presença de serviços de saúde na cidade é outro ponto que contribui para a centralidade da cidade, com a presença de hospitais, de clínicas e de médicos especializados, gerando outras funções como laboratórios, farmácias, entre outros e atraindo pessoas de diversos municípios. Sobre os equipamentos de saúde em Vitória da Conquista, Ferraz (2009) esclarece que:

A instalação de equipamentos de alta tecnologia para diagnóstico por imagem fortalece fixos e estimula os fluxos. Com a instalação de equipamentos em clínicas e hospitais em Vitória da Conquista para a realização de exames de ultrassonografia, tomografia, ressonância magnética, por exemplo, pacientes do município e também de municípios do seu entorno que, antes, precisavam se deslocar, principalmente para Salvador, passaram a realizar os exames em Vitória da Conquista. Existe, assim, um reforço do nó da rede. Uma rede que ao mesmo tempo inclui e exclui. Aqueles que tem dinheiro para pagar os exames ou pagar um plano de saúde que os financie 
estão incluídos. Já aqueles que não tem essa condição, mesmo havendo o equipamento instalado na cidade, estão excluídos. Relatos de entrevistados expõem a dificuldade do acesso que, às vezes, gera a impossibilidade de realização de exames com a utilização de aparelhos sofisticados por meio do SUS (FERRAZ, 2009, p. 156-157).

De fato, tanto os serviços educacionais como os de saúde geram a presença de outras funções associadas que dinamizam o comércio e os serviços movimentando a cidade que cada dia fortalece sua centralidade.

\section{Aracaju e sua centralidade urbana}

Aracaju, município que sedia a capital de Sergipe, apresenta uma área de 181,8 $\mathrm{km}^{2}$ e está situado na porção leste do Estado, contando com uma população estimada em 657.013 habitantes, conforme estimativas do IBGE, para 2019 (Figura 5). A cidade integra uma área metropolitana formada por quatro municípios: Aracaju, Barra dos Coqueiros, Nossa Senhora do Socorro e São Cristóvão (FRANÇA,1997).

Mapa 4 - Localização do Estado de Sergipe e Aracaju no Brasil

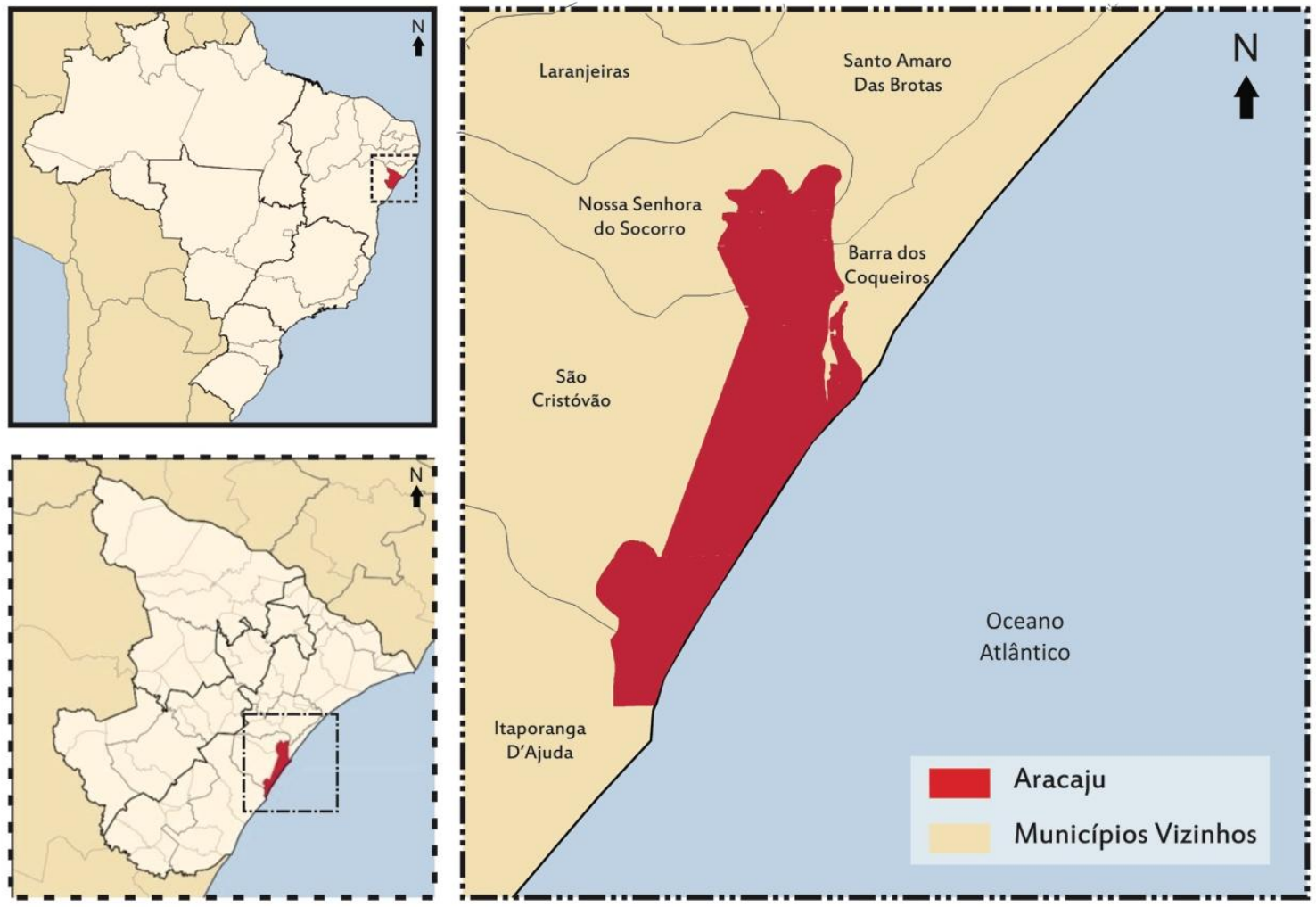

Fonte: França, (2011)

A cidade foi fundada em 17 de março de 1855, para ser a capital em substituição a São Cristóvão que atravessava um período de decadência (FRANÇA, 1997). A partir do século XX, a cidade se firma no cenário econômico e político estadual e consolida sua posição como principal centro urbano do Estado de Sergipe. Em 1982, a Prefeitura 
Municipal definiu que todo o território municipal é área urbana, favorecendo o espraiamento da cidade e a valorização da terra. Na economia estadual o município também se destaca produzindo 42,4\% do PIB estadual, conforme dados de 2016, demonstrando uma força do município no conjunto da economia estadual (IBGE, 2019).

Mapa 5 - Área de influência de Aracaju - 2008

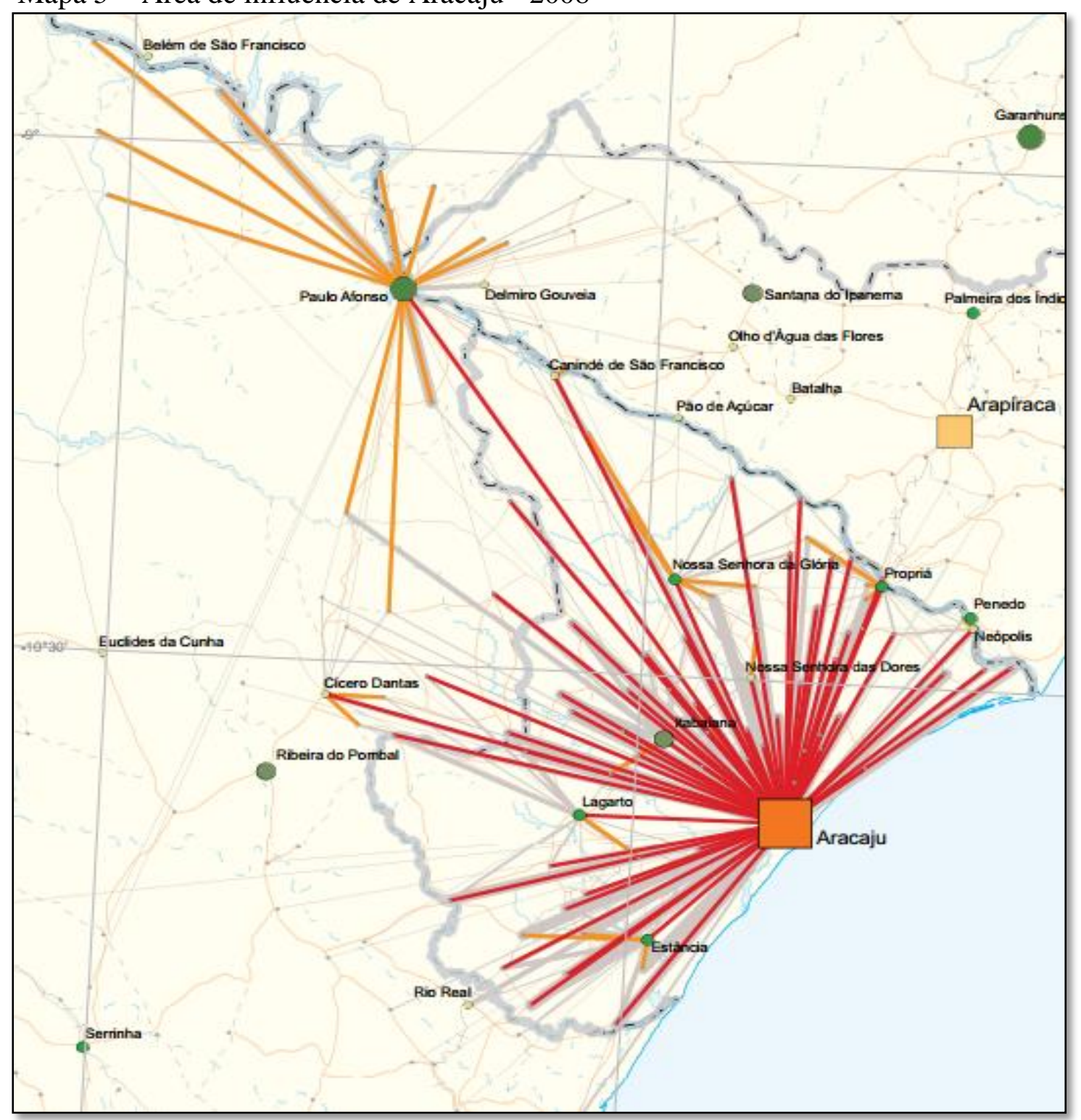

Fonte: IBGE, 2008.

Aracaju faz parte de um subsistema urbano primaz, indicando uma macrocefalia urbana, isto é uma cidade forte, comandando um sistema formado por pequenas cidades (DINIZ,1987). A primazia da cidade é cada vez mais fortalecida pelas facilidades de acesso e de comunicação, cobrindo todo os setenta e quatro municípios sergipanos e os municípios limítrofes da Bahia, no sentido oeste, totalizando uma influência sobre 93 municípios (IBGE, 2008). 
Inserida no sistema urbano brasileiro, como capital regional, a cidade de Aracaju se relaciona com o substrato superior da rede urbana, integrando a área de influência da metrópole regional Salvador, com a qual mantém fortes conexões através dos fluxos de mercadorias, informações e de pessoas. Além disso, Aracaju mantém fortes relações externas com São Paulo, Brasília, Rio de Janeiro, Recife, Feira de Santana, Paulo Afonso, Arapiraca e Petrolina, Juazeiro, Ribeira do Pombal e Alagoinhas (IBGE, 2008)

Mapa 6- Aracaju, Conexões Externas, 2008

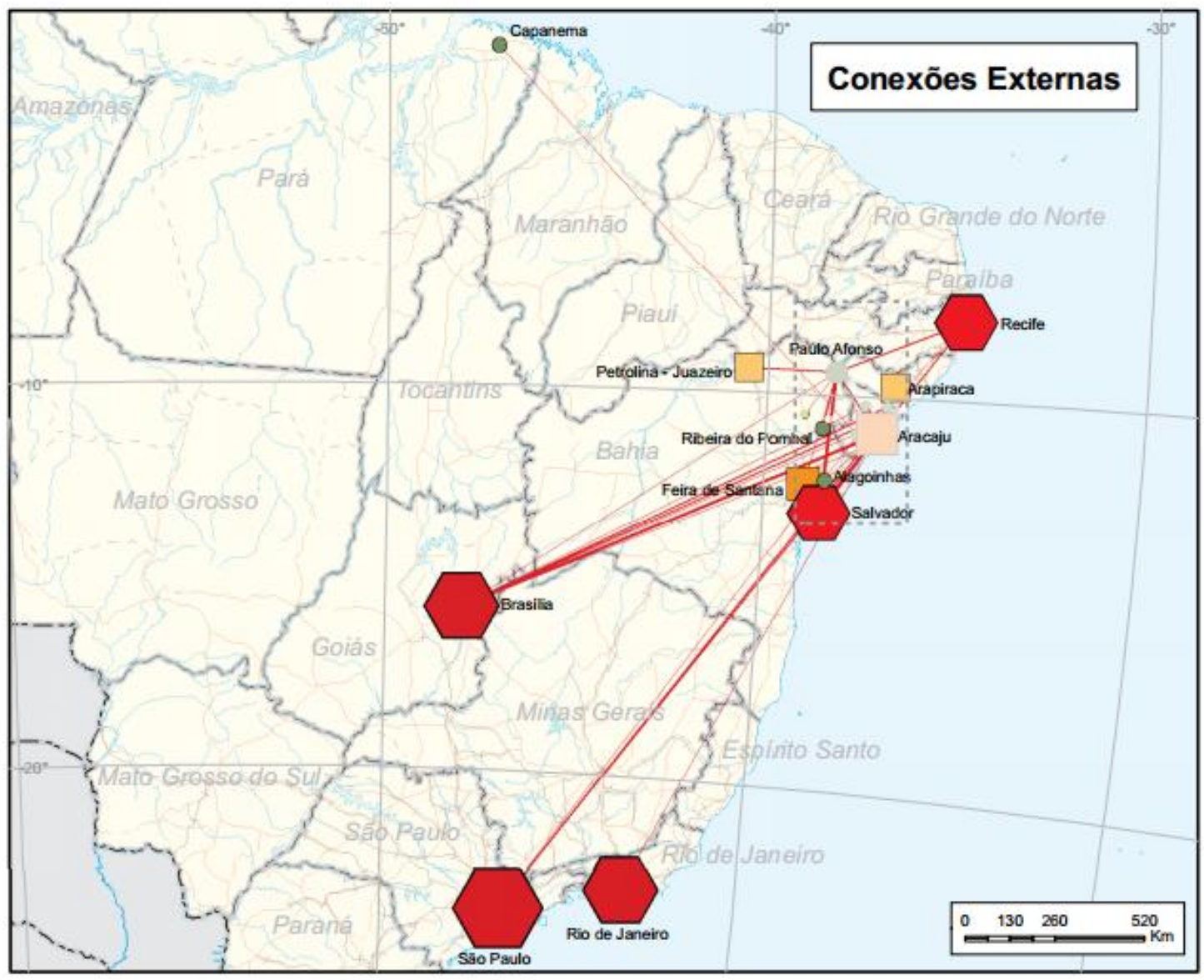

Fonte: IBGE, ( 2008)

A exiguidade do território sergipano, com apenas $21.926 \mathrm{~km}^{2}$, contribui para essa consolidação da primazia, tendo em vista uma rede rodoviária estadual que facilita as ligações com todas as sedes municipais sergipanas, avançando sobre municípios baianos, situados nas circunvizinhanças do Estado, a exemplo de Rio Real, Conde, Jandaíra, ao sul, Adustina, Paripiranga, Fátima, Heliópolis, Jeremoabo, Itapecuru, Olindina, Santa Brígida e Cel. João Sá, Glória, Paulo Afonso, ao oeste e, ao norte, os municípios alagoanos de Piranhas e Porto Real de Colégio (IBGE, 2008). Um sistema de rodovias radial e as pequenas distâncias reforçam a centralidade, exigindo a dotação 
de infraestrutura capaz de atender a um volume de pessoas bem maior do que sua população, pressionando sua infraestrutura (FRANÇA, 2013).

O Centro da cidade vai se caracterizar pela presença de funções comerciais e de serviços, sobretudo destinada as classes populares. A manutenção de uma estação rodoviária, no Centro, contribui para a intensificação do movimento pendular, inclusive com a presença vans e de táxis que levam a população para seus municípios. A formação de subcentros está presente, tendo em vista o tamanho da cidade e o volume de população. Assim, o principal subcentro é o Bairro Siqueira Campos, com presença de intenso comércio e prestação de serviços. A presença dos Shoppings também atrai população de outros municípios na busca de bens, de serviços e de lazer. No Bairro Jardins, observa-se uma nova centralidade a partir da presença de funções comerciais e de serviços destinados as classes média e alta.

As funções administrativas são um forte componente na cidade com todo o staff do governo estadual concentrado na cidade, além das funções do governo federal que atraem grande número de pessoas, movimentando a cidade.

As funções de educação e de saúde atraem um grande contingente que diariamente se desloca para a cidade em busca desses serviços. A presença de universidades e de escolas de ensino superior são responsáveis por fortalecer a centralidade da cidade distribuindo por vários bairros, intensificando a formações de subcentros no interior da malha urbana. Na cidade estão presentes quatro universidades sendo uma pública e três particulares, além de diversas faculdades e colégios de ensino médio que atraem pessoas de todo território sergipano, numa migração pendular e de pessoas de outros estados que migram para a cidade em busca dessas funções. Na cidade é grande o número de ônibus escolares que nos três turnos trazem alunos, sendo mais expressivo no turno noturno. Essas funções de educação também tem contribuído para a organização do espaço e formação de subcentros, a exemplo do que vem ocorrendo no Bairro Farolândia, no entorno da Universidade Tiradentes. De fato, no Bairro Farolândia, ao longo das avenidas, diversas atividades comerciais e de serviços se destacam atraindo pessoas dos bairros vizinhos (FRANÇA,2013).

A presença de hospitais públicos na cidade também são responsáveis por fluxos procedentes de todos os municípios sergipanos e daqueles das circunvizinhanças do Estado. Dois hospitais públicos se destacam: o Hospital de Urgência de Sergipe (HUSE), o Hospital Universitário, ligado a Universidade Federal de Sergipe e mais três privados: O Hospital das Clínicas Dr. Augusto Leite (conhecido como Cirurgia), o 
Hospital São Lucas e o Primavera, além de outros menores e diversas clínicas dispersas por duas áreas com tendência a especialização em serviços de saúde: a primeira situada entre os bairros São José e Salgado Filho e a outra no bairro Siqueira Campos, voltada para as classes populares. No Bairro Cirurgia, no entorno do Hospital das Clínicas (Cirurgia), também se observa uma centralidade ligada à saúde, com a presença de Clínicas médicas, consultórios médicos, óticas, farmácias, instituições filantrópicas, com ações ligadas a saúde, a exemplo da AMO (Associação dos Amigos da Oncologia) e FEFECC (Legião Feminina de Educação e Combate ao Câncer, restaurantes, lanchonetes, estacionamentos, lojas, boutiques entre outros, gerando intenso fluxo de pessoas, diariamente.

\section{Considerações finais}

As cidades são portadoras de centralidade, a partir da presença de fixos (funções) que atraem fluxos oriundos de outras localidades e dão dinâmica à vida local, com reflexos sobre a região onde está inserida. A centralidade é uma característica inerente às cidades, sendo responsável pelo crescimento de suas atividades econômicas, resultando no seu crescimento.

As cidades alvo deste artigo, isto é, Vitoria da Conquista (BA) e Aracaju (SE) apresentam situação diferenciada, embora apresentem semelhanças sobretudo no tocante a força das funções de educação e de saúde, ambas com capacidade de atração de grandes contingentes procedentes de áreas distantes.

Vitória da Conquista é uma cidade que se destaca no Sudoeste baiano, com forte influência sobre uma Região que compreende mais de 100 municípios baianos. Como capital regional, se destaca entre as cidades mais importantes da Bahia, integrando o ranking das cidades que mais crescem no país. Sua posição privilegiada entre eixos rodoviários que ligam diferentes áreas do país proporcionam condições para intensificar essa dinâmica e centralidade.

Aracaju, capital estadual de Sergipe, a cada dia intensifica sua primazia sobre o território no qual está situada, facilitada pela rede rodoviária, pela exiguidade do território sergipano e pela extensão do território baiano e a distância desses lugares da capital, Salvador. A proximidade favorece as relações com Sergipe e, sobretudo, com Aracaju. No Subsistema urbano Aracaju, Paulo Afonso é a segunda cidade, embora esteja fora dos limites sergipanos. 
A centralidade dessas duas cidades tende a aumentar em decorrência das facilidades de contato com suas regiões de entorno, assegurada pela rede rodoviária e a modernização dos transportes.

\section{Referências}

BRASIL. Atlas Nacional de Comércio e Serviços. Brasília, DF: MDIC, 2008.

DINIZ, José Alexandre F. O subsistema urbano-regional de Aracaju. Recife: SUDENE, 1987.

FERRAZ, Ana Emília de Quadros. O espaço em movimento: o desvelar da rede nos processos sociotécnicos do sistema de saúde de Vitória da Conquista-Bahia. Tese (Doutorado em Geografia). Universidade Federal de Sergipe, 2009.

FRANÇA, Sarah Lúcia Alves. A produção do espaço na zona de expansão de Aracaju/SE: dispersão urbana, condomínios fechados e políticas públicas. Dissertação (Mestrado em Arquitetura e Urbanismo) - Universidade Federal Fluminense, 2011.

FRANÇA, Vera Lúcia Alves. Aracaju: Estado e metropolização. Rio Claro, SP Universidade Estadual Paulista Júlio de Mesquita, 1997.

FRANÇA, Vera Lucia Alves. PREFEITURA MUNICIPAL DE ARACAJU. Diagnóstico da cidade de Aracaju. Aracaju PMA, 2014.

GUSMÃO, Adriana David Ferreira. Ensino superior e produção do espaço regional. Dissertação (Mestrado em Geografia)- Núcleo de Pós-Graduação em GeografiaNPGEO, Universidade Federal de Sergipe, São Cristóvão, 2009.

IBGE. Censo demográfico, 2010. Rio de Janeiro: IBGE, 2010.

IBGE. Estimativas de população, 2019. Rio de Janeiro: IBGE, www.ibge.bov.br/cidades, acesso em 20/09/2019.

IBGE. Área de influência das cidades brasileiras. Rio de Janeiro: IBGE, 2008.

IBGE.Contas nacionais, produto interno bruto, 2016. Rio de Janeiro: IBGE, www.ibge.bov.br/cidades, acesso em 20/09/2019.

LOPES, Roberto Paulo Lopes Machado. Cluster de ensino superior: uma estratégia alternativa de desenvolvimento. Conjuntura \& Planejamento. Salvador, nº 96, 2002.

SANTOS, Milton. A natureza do espaço, razão e emoção. São Paulo: HUCITEC, 1996. 